\title{
IgG and IgM Pneumococcal Polysaccharide Antibody Responses in Infants
}

\author{
DOUGLAS J. BARRETT, CARLOS G. LEE, ARTHUR J. AMMANN, AND ELIA M. AYOUB \\ Division of Immunology and Infectious Diseases, Department of Pediatrics, University of Florida College of \\ Medicine, Gainesville, Florida 32610 and Division of Immunology, Department of Pediatrics, University of \\ California, San Francisco, San Francisco, California 94117
}

\begin{abstract}
The ontogeny of human antibody responses to pneumococcal polysaccharide antigens was studied by determining whether the age at immunization affects the level and/or immunoglobulin isotype of antibody produced. Twenty-nine healthy infants between 2 and 18 months of age and 13 normal adults were studied. Responses were found to vary markedly with the age at the time of immunization and with the pneumococcal serotype tested. Three general patterns of isotype-specific antibody response were observed in the infants: a high response in IgG antibody occurred as early as 2 months of age following immunization with type 3 pneumococcal polysaccharide; little or no response was noted in either IgG or IgM antibody with types 6, 18, and 19; and intermediate responses with IgM antibody increases greater than IgG increases were found for type 23. These data suggest that different factors control the immunologic response of infants to various pneumococcal polysaccharide serotypes following immunization at various ages. (Pediatr Res 18:1067-1071, 1984)
\end{abstract}

\section{Abbreviations}

PnPs, pneumococcal polysaccharide

ELISA, enzyme-linked immunosorbent assay

Infection with Streptococcus pneumoniae is among the most common causes of otitis media, pneumonia, bacteremia, and meningitis in pediatric patients $(2,13)$. Despite early antibiotic therapy, morbidity and mortality from pneumococcal infections are unacceptably high, particularly in those under 2 years of age and in patients with anatomic or functional asplenia $(4,6,16)$. These considerations, along with the emergence of antibiotictolerant and resistant organisms $(22,25)$, increase the need for an effective pneumococcal vaccine. PnPs vaccines have been shown to be both immunogenic and protective in young adults and in children over the age of 2 years $(1,3,14,17,23)$. However, infants under 2 years may respond poorly to the vaccine (9). A lack of knowledge of the immunobiology of human responses to PnPs antigens has precluded our understanding the reasons for poor responses in infants and has hindered the development of effective immunizing techniques.

To further characterize human immune responses to pneu-

Received August 30, 1983; accepted March 12, 1984

Correspondence may be addressed to Douglas J. Barrett, M.D., Box J-295, JHMHC, Department of Pediatrics, University of Florida College of Medicine, Gainesville, FL 32610.

This work was supported in part by New Investigator Award AI 17658-02 (D. J. B.) and by the Department of Pediatrics and the Division of Sponsored Research, University of Florida. This work was presented in part before the Society for Pediatric Research, Washington, D. C., April 19, 1982. mococcal polysaccharides, our previous studies have focused on defining the immunoglobulin isotype of antibody produced in older children and adults. In contrast to the mouse model where mainly IgM antibody is produced $(5,10)$, humans respond with both $\operatorname{IgM}$ and IgG classes $(7,8)$. Furthermore, there appear to be distinct differences in the patterns of response to the various serotypes. The present studies were performed to determine whether the level and immunoglobulin isotype of antibody produced varied with the age at the time of immunization as well as with each individual pneumococcal serotype.

\section{MATERIALS AND METHODS}

Study population. Twenty-nine healthy infants between 2 and 18 months of age were screened for pre-existent acute or chronic disease prior to immunization. Infants were assigned to three groups according to age: 2 to 6 months, 7 to 12 months, and 13 to 18 months inclusively. There were 12,7 , and 10 subjects in each group, respectively. In addition, 13 normal healthy adults ages 22 to 34 years were studied. All subjects or their guardians gave their informed consent prior to participation in the study as approved by the Institutional Review Board.

Pneumococcal polysaccharide vaccine. Subjects were immunized subcutaneously with an octavalent vaccine (Eli Lilly and Co., Indianapolis, IN) containing $50 \mu \mathrm{g}$ of polysaccharide from each of the pneumococcal serotypes $1,3,6 \mathrm{~A}, 7 \mathrm{~F}, 14,18 \mathrm{C}, 19 \mathrm{~F}$, and $23 \mathrm{~F}$ (Danish nomenclature) in a total volume of $0.5 \mathrm{ml}$. The parents were instructed to report any local or systemic untoward effects of the vaccine at the time of its occurrence or at the time that postimmunization blood samples were obtained.

A serum sample was obtained prior to immunization and 3 to 4 weeks after immunization. All samples were stored at $-20^{\circ} \mathrm{C}$ until tested.

ELISA for anti-PnPs antibody. Pre- and postimmunization serum samples were measured simultaneously for levels of antibody to individual PnPs antigens by the ELISA technique as previously described (8). This system has been expanded to include the detection of antibody to serotypes $3,6,18,19$, and 23. The purified capsular polysaccharide antigens were prepared by Merck Sharp and Dohme Research Laboratories and were obtained from the American Type Culture Collection. The antigens had been previously shown to contain less than $1 \%$ contaminating C-polysaccharide by direct assay (Dr. Alan Woodhour, personal communication). Preliminary experiments in our laboratory demonstrated the antigens to be free of significant quantities of contaminating cell wall C-polysaccharide by failure to interact with $\mathrm{C}$-reactive protein in a double antibody ELISA. Serum antibody levels were expressed as the endpoint of titration, which was defined as the highest dilution of serum that produced an optical density in antigen-coated test wells that was twice the optical density for the same dilution of serum in control wells. Utilizing affinity purified IgG antibody to type $3 \mathrm{PnPs}$, the lower 
limit of detection in the assay was approximately $0.05 \mu \mathrm{g} / \mathrm{ml}$. Results for the subject groups are presented as the geometric mean of endpoint antibody titers for preimmunization and postimmunization samples. As a further measure of response or vaccine immunogenicity, the ratio of the postimmunization to preimmunization antibody titers, or -fold change in titer, was

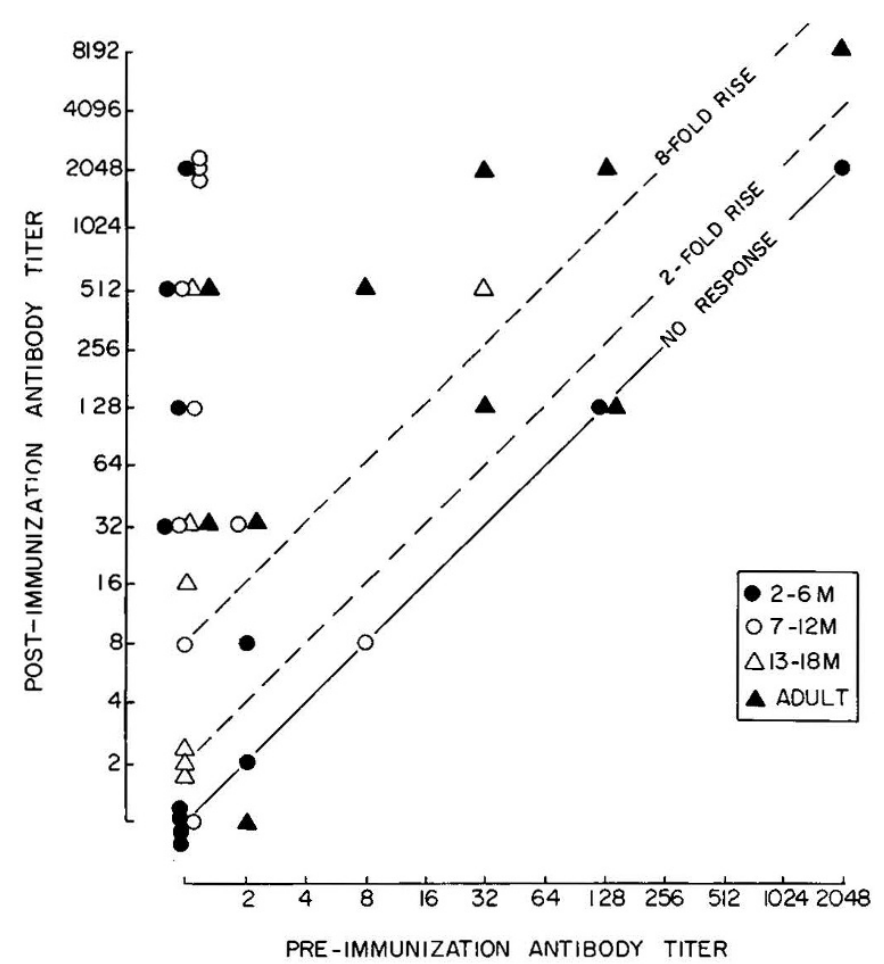

Fig. 1. Antibody titers to Pneumococcus type 3 of infants and adults before and after immunization. Each subjects' pre- and postimmunization antibody level generates a single point on the graph. The symbols indicate the age at which immunization was given. The solid line through the points of equal concentration on both axes corresponds to "no response." Dashed lines parallel to and above the no-response line correspond to a 2 -fold and 8 -fold rise in antibody titer. calculated for each individual (20). Each individual's preimmunization and postimmunization sera were assayed simultaneously on a single plate to minimize variability. The within-assay coefficient of variation for endpoint titer was 0.076 . Replicate assays of a single serum tested on different days gave a coefficient of variation of 0.24 for endpoint titer. Replicate determinations of preimmunization to postimmunization -fold increases in titer for paired sera gave a coefficient of variation of 0.14 . Therefore, for paired sera from a given subject assayed simultaneously, a 2fold or greater change in titer was considered significant.

Analysis of the data was performed using a computer-assisted statistical calculation software package (Ed-Sci Development; Modesto, CA) based on standard statistical techniques (24). Preimmunization versus postimmunization antibody levels for each serotype and each immunoglobulin isotype within a given age group were compared using the $t$ test for paired data. Analysis of antibody titer versus age at immunization was determined independently for each serotype and each isotype by one-way analysis of variance. Correlation between the pre- to postimmunization change in antibody titer and the age at immunization was tested by linear regression analysis.

\section{RESULTS}

Reactions to the immunization consisted of mild local pain at the site of injection and fever which was no higher than $38^{\circ} \mathrm{C}$. No systemic adverse reactions were reported.

Antibody responses of the study subjects, in both adults as well as children, were highly variable. As shown for type 3 in Figure 1, some individuals responded well even when immunized as early as 2 months of age, whereas others (including some adults) responded poorly. Variation between subjects was greatest for type 3 but a similar effect was noted for each serotype tested.

Mean preimmunization and postimmunization titers for antibody to type 3 PnPs are shown in Figure 2. The mean titers of IgG antibody to type 3 increased following immunization in each of the infant groups as well as in the adults. The mean postimmunization IgG titers of each of the infant groups were not significantly different from the mean postimmunization titer for adults. Significantly higher titers of IgM antibody to type 3 were found in the 7-12-month and adult groups following immunization, whereas no change was noted in the 2-6-month or 13-18-month groups. Mean IgM titers for 2-6-month and 13-

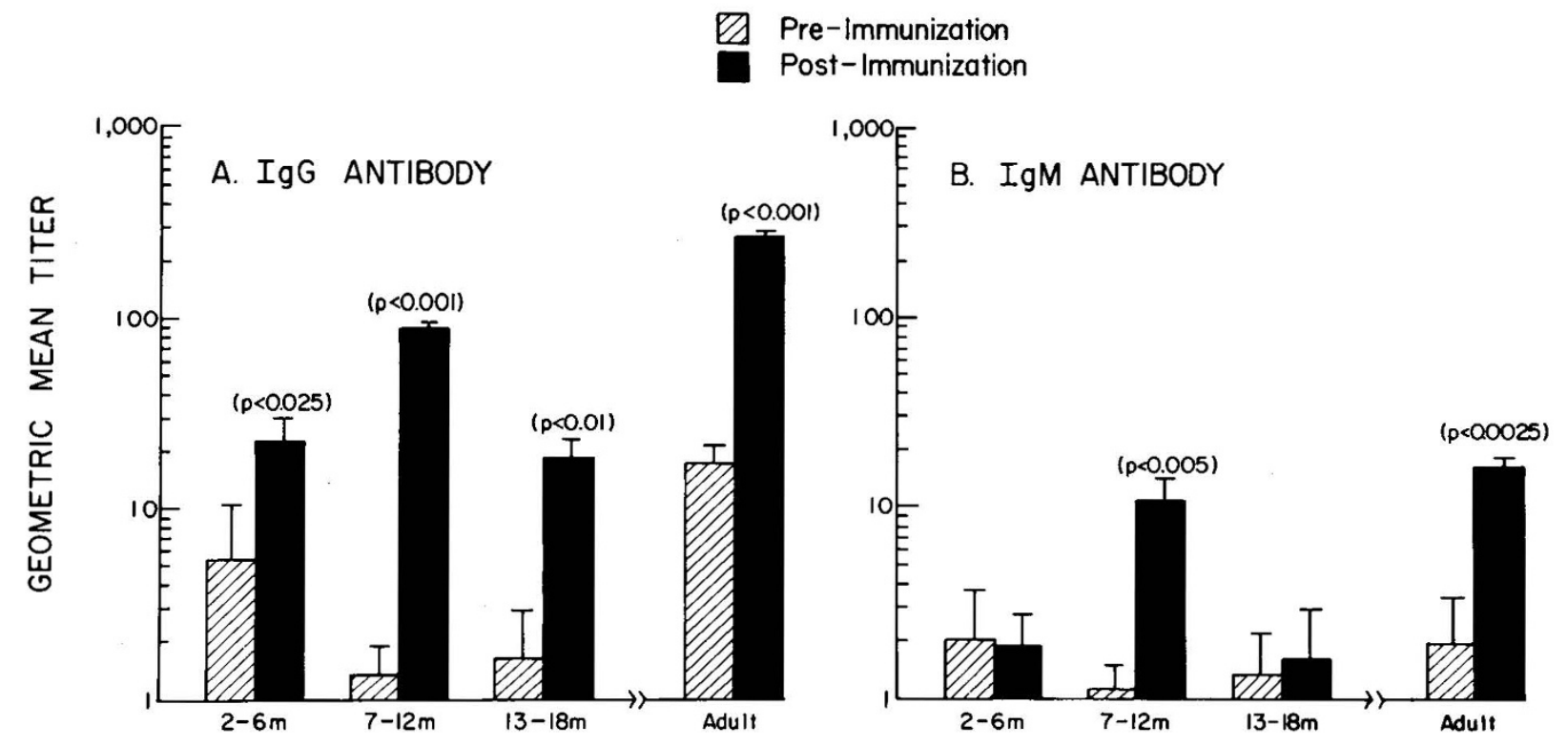

Fig. 2. Antibody titers to PnPs type 3 before immunization (ש्Z) and after immunization $(\square)$. Geometric mean titers of $\operatorname{IgG}(A)$ and $\operatorname{IgM}(B)$ antibodies for subjects immunized at 2-6, 7-12, and 13-18 months or adults are shown. Significant differences between pre- and postimmunization geometric mean titer within each age group are shown. 


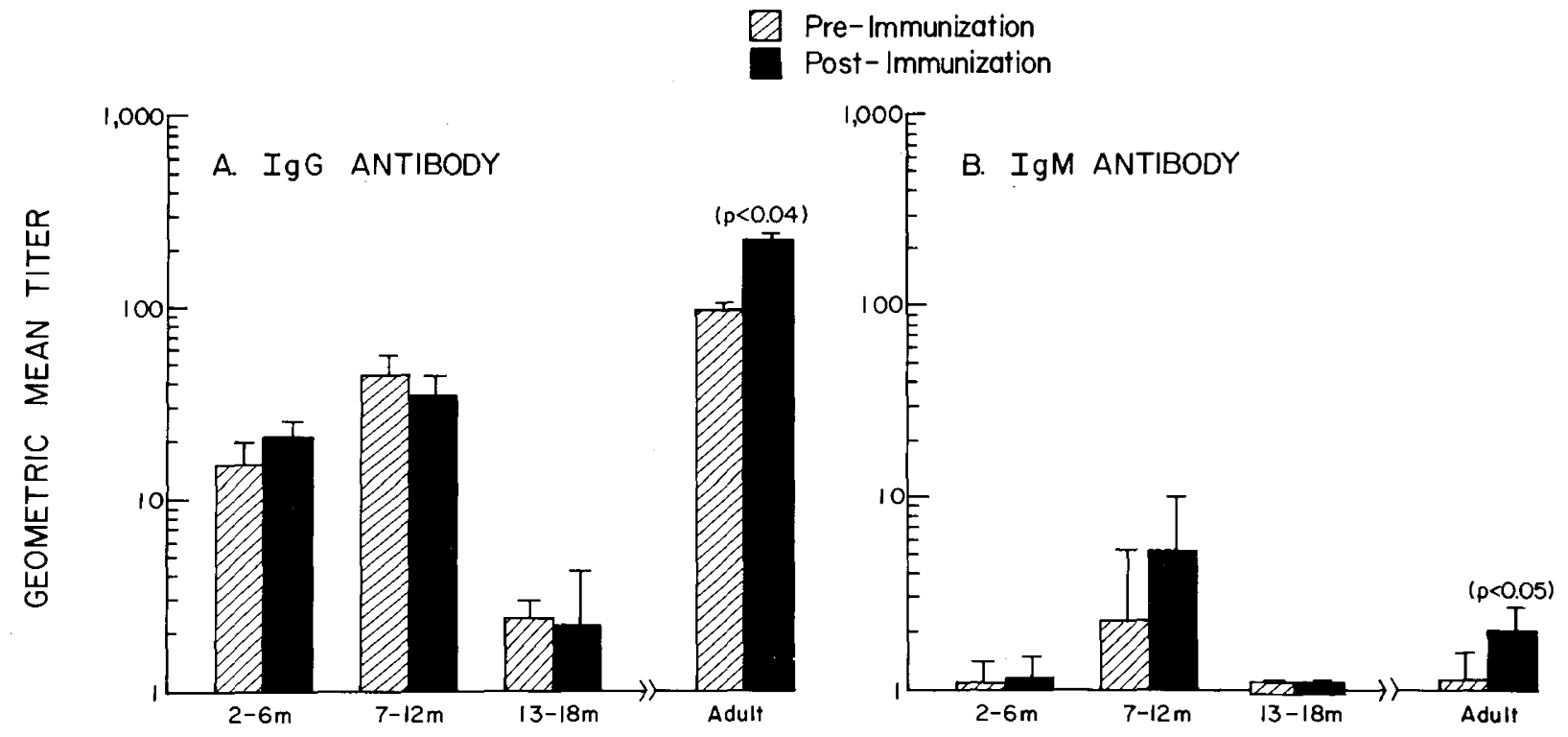

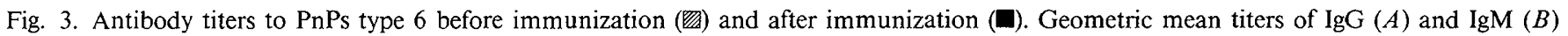
antibodies for subjects immunized at 2-6, 7-12, and 13-18 months or adults are shown. Significant differences between pre- and postimmunization geometric mean titer within each age group are shown.

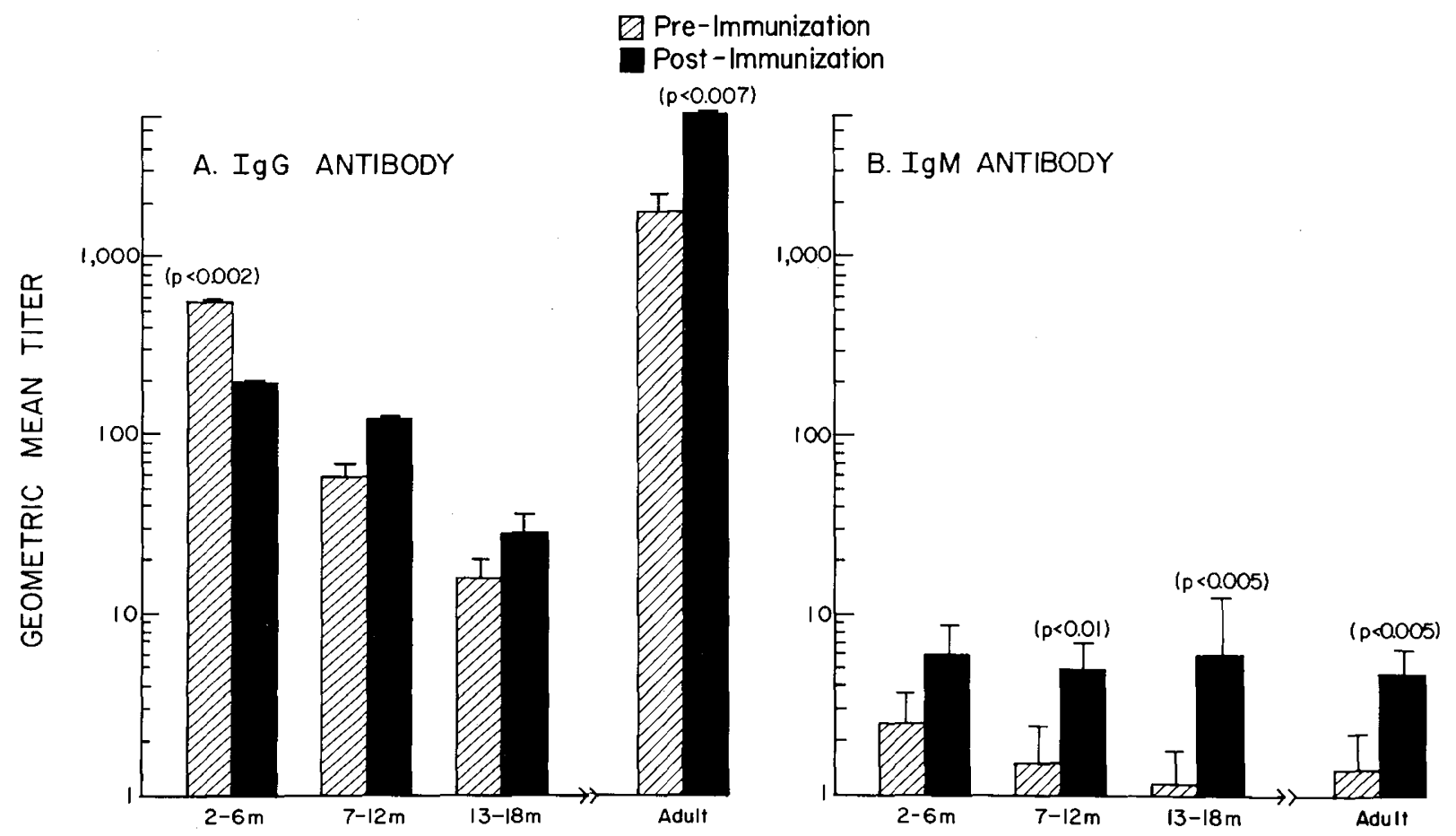

Fig. 4. Antibody titers to PnPs type 23 before immunization (ש्Z) and after immunization $(\square)$. Geometric mean titers of $\operatorname{lgG}(A)$ and $\operatorname{lgM}(B)$ antibodies for subjects immunized at 2-6,7-12, and 13-18 months or adults are shown. Significant differences between pre- and postimmunization geometric mean titer within each age group are shown.

18 month groups were significantly lower than adult levels after immunization ( $p<0.025$ and $p<0.05$, respectively).

Antibody titers for type 6 PnPs are shown in Figure 3. High mean titers of preformed IgG antibody was found in the 2-6month, 7-12-month, and adult groups. In contrast to the adults, and in contrast to the results for type 3, postimmunization for IgG antibody levels in infants were similar to preimmunization values, regardless of the age at immunization. The lack of response in infants was probably not simply due to the presence of preformed antibody, because the 13-18-month group who had a low preimmunization level did not respond to the immunization. While the adult group demonstrated a small but statis- tically significant increase in $\operatorname{IgM}$ antibody following immunization, no increase in mean IgM titer in any of the infant groups was found.

The pattern of titers for type 18 and type 19 PnPs were similar to that of type 6 (data not shown). Adults responded with increases in the mean titers for both $\operatorname{IgG}$ and $\operatorname{IgM}$ antibody to type 18 and with increases in IgG but not IgM antibody to type 19. Infants showed no change in mean titer of antibody to either serotype.

Geometric mean titers for type 23 are shown in Figure 4. Adult IgG anti-type 23 titer was increased following immunization while that of the infants was not. Unlike the other serotypes 
tested, significantly higher mean IgM titers were found in the 712-month, 13-18-month, and the adult groups after immunization and the mean IgM titers for each of the infant groups were similar to the adult level.

As an alternative measure of vaccine immunogenicity, the mean change in antibody titer for each of the five PnPs serotypes was examined (25). Three general patterns of response were observed (Figure 5). Large increases in IgG antibody to type 3 were found. There was no difference in mean change in IgG titer between the adults and the infants immunized at any age, while the mean increase in IgM antibody to type 3 for the 2-6 month and the 13-18-month groups was statistically lower than adults. In contrast to the pattern with type 3 , the mean changes in titer for antibody to types 6,18 , and 19 were low in the infants immunized at any age. The third general pattern of response was observed with type 23 . The mean-fold increase in IgG antibody was similar to adults with immunization after 2-6 months of age. A significant correlation between -fold increase in IgG antibody to type 23 and age of immunization was noted by linear regression analysis $(r=0.294, p=0.03)$. In contrast to IgG, IgM increases to type 23 in each infant group were consistently greater than 2-fold and were similar to the response of the adults.

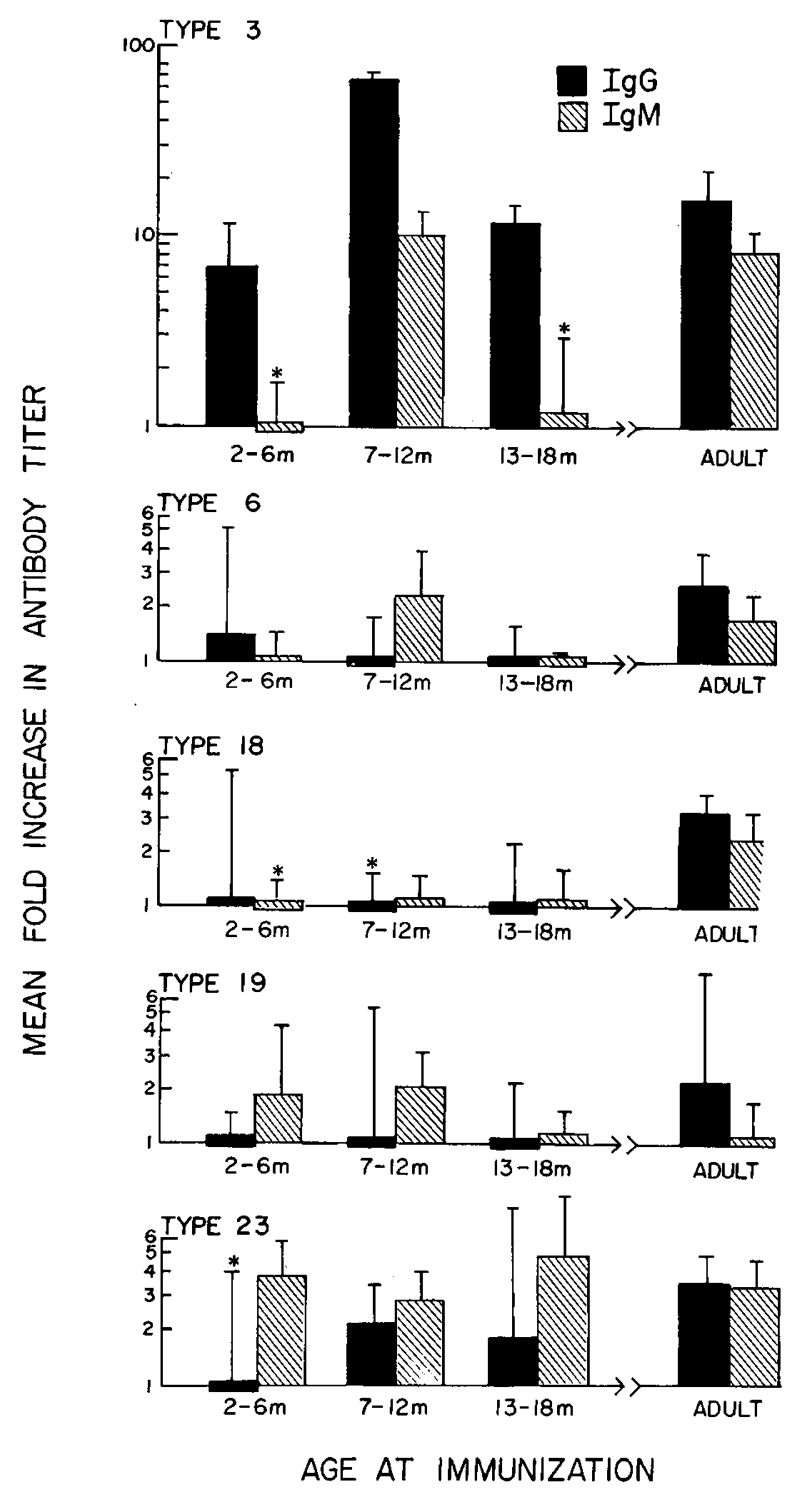

Fig. 5. Mean -fold increase in antibody titer for five PnPs serotypes. The mean -fold increases ( \pm SEM) in IgG antibody $(\square)$ and IgM antibody (ש्Z) for each serotype tested are plotted versus age of immunization. Statistically significant differences between infants and adults by oneway analysis of variance are noted. ${ }^{*}, p<0.05$.

\section{DISCUSSION}

The results of these studies emphasize the complexity of the human immune response to PnPs antigens. Both the antibody level and the isotype vary with age at the time of immunization as well as with the pneumococcal serotype. We have demonstrated that at least three separate patterns of response can be observed with PnPs immunization before 2 years of age: high responses, particularly with large increases in IgG antibody, for type 3; low responses with little or no change in $\operatorname{IgG}$ or IgM antibody for types 6,18, and 19; and intermediate responses as with type 23 , where IgM increases occurred as early as 7 months and where 2- to 4-fold increases in IgM antibody were observed consistently in the infant groups.

Our findings using the isotype-specific ELISA system confirm and extend the results of other investigators who have used assays that measure total (IgG and $\operatorname{IgM}$ ) antibody in infants under 2 years of age. Utilizing the radioimmunoassay of Schiffman et al. (18), previous studies have shown that a significant percentage of infants under 1 year can respond to type 3 antigen while the response to type 6 is consistently very low and the responses to types 18,19 , and 23 are limited and more variable $(9,15,19$, 21). Using an indirect hemagglutination assay, Cowan et al. (11) found that $90 \%$ of 3 -month-old infants responded to type 3 but that antibody titers to types $6,18,19$, and 23 did not differ from those of saline-immunized controls. The radioimmunoassay measures both IgM and IgG classes of antibody (18). Hemagglutination can be due to IgM or IgG antibody, especially when high levels of $\mathrm{IgG}$ antibody are present. Our demonstration of the nonuniform isotype distribution of antibody to the various PnPs serotypes suggests that the disparities in results between the previous studies may be explained by differences in assay systems.

Because of the serotype-dependent variability in both the level and isotype of antibody, responses to PnPs antigens in infants must be interpreted with caution. Our results support the conclusion of Giebink et al. (12) that immunologic responses to polyvalent PnPs vaccines cannot be assessed solely on postimmunization antibody levels to a single serotype, on mean change in antibody level for a single serotype, or on a summarized analysis based on the mean concentration of antibody to many different pneumococcal serotypes in serum from an individual. The timing of postimmunization serum samples raises additional cautions. Pneumococcal immunization in infants may represent a primary challenge, whereas in the adults it may be a secondary challenge. Therefore, it is possible that an effective IgM to IgG isotype switch may not have occurred in the infants by 3 or 4 weeks postimmunization. Although no secondary or anamnestic response, with an attendant IgM to IgG isotype switch, is thought to occur with PnPs antigens, studies using assays for total (IgG and (gM) antibody may overlook this possibility.

It is apparent from these studies that an age-dependent increase in the antibody responsiveness of human infants is not universal for all PnPs serotypes. Further, our data demonstrate that the immunoglobulin isotype of antibody produced is not the same for all serotypes at all ages. These results suggest that the serotypespecific PnPs antibody response of humans immunized at different ages is controlled and regulated by different factors. Further delination of those mechanisms may help us understand the poor polysaccharide antibody responses of infants and children.

Acknowledgments. The authors wish to thank Ms. Oonagh Kater and her editorial staff for assistance in preparation of the manuscript.

\section{REFERENCES}

1. Ammann AJ, Addiego J, Wara DW, et al 1977 Polyvalent pneumococcal polysaccharide immunization of patients with sickle-cell anemia and patients with splenectomy. N Engl J Med 297:897

2. Austrian R 1981 Some observations on the Pneumococcus and on the current status of pneumococcal disease and its prevention. Rev Infect Dis 3:S1

3. Austrian R, Douglas RM, Schiffman G et al 1976 Prevention of pneumococcal pneumonia by vaccination. Trans Assoc Am Physicians 89:184 
4. Austrian R, Gold J 1964 Pneumococcal bacteremia with especial reference to bacteremic pneumococcal pneumonia. Ann Intern Med 60:759

5. Baker PJ, Amsbough DF, Stashak PW, et al 1981 Regulation of the antibody response to pneumococcal polysaccharide by thymus-derived cells. Rev Infect Dis 3:332

6. Barrett-Connor E 1971 Bacterial infection and sickle cell anemia: an analysis of 250 infections in 16 patients and a review of the literature. Medicine $50: 97$

7. Barrett DJ, Ammann AJ 1981 Pneumococcal vaccine in sickle cell disease: IgG and IgM antibody response. Rev Infect Dis 3:S179

8. Barrett DJ, Ammann AJ, Stenmark S, Wara DW 1980 Immunoglobulin G and $\mathrm{M}$ antibodies to pneumococcal polysaccharides detected by enzymelinked immunosorbent assay. Infect Immun 27:411

9. Borgono JM, McLean AA, Vella PP, et al 1978 Vaccination and revaccination with polyvalent pneumococcal polysaccharide vaccines in adults and infants. Proc Soc Exp Biol Med 157:148

10. Braley-Mullen H 1980 Direct demonstration of specific suppressor T-cells in mice tolerant to Type III and pneumococcal polysaccharide. Two-step requirement for development of detectable suppressor cells. J Immunol 125:1849

11. Cowan MJ, Ammann AJ, Wara DW, et al 1978 Pneumococcal polysaccharide immunization in infants and children. Pediatrics 62:721

12. Giebink GS, Le CT, Spika JS 1981 Summarized vs. type-specific analysis of antibody to pneumococcal capsular polysaccharides. Rev Infect Dis 3:S43

13. Klein JO 1981 The epidemiology of pneumococcal disease in infants and children. Rev Infect Dis 3:246

14. Landesman SH, Schiffman G 1981 Assessment of the antibody response to pneumococcal vaccine in high-risk populations. Rev Infect Dis 3:S180
15. Makela PH, Herva E, Sibakov M, et al 1980 Pneumococcal vaccine and otitis media. Lancet 1:547

16. Powars DR 1975 Natural history of sickle cell disease-the first ten years. Semin Hematol 12:267

17. Rytel MW 1982 Pneumococcal infections and pneumococcal vaccine: an update. Infect Contr 3:295

18. Schiffman G, Douglas RM, Bonner MJ, et al 1980 A radioimmunoassay for immunologic phenomena in pneumococcal disease and for the antibody response to pneumococcal vaccines. I. Method for the radioimmunoassay of anticapsular antibodies and comparison with other techniques. J Immunol Methods 33:133

19. Sell SH, Wright PF, Vaughn WK, et al 1981 Clinical studies of pneumococcal vaccines in infants. I. Reactogenicity and immunogenicity of two polyvalent polysaccharide vaccines. Rev Infect Dis 3:S97

20. Siber GR, Ransil BJ 1983 Methods for the analysis of antibody responses to vaccines or other immune stimuli. Methods Enzymol 93:4

21. Teele DW, Klein JO, Bratton L, et al 1981 Use of pneumococcal vaccine for prevention of recurrent acute otitis media in infants in Boston. Rev Infect Dis 3:S113

22. Ward J 1981 Antibiotic-resistant Streptococcus pneumoniae: clinical and epidemiological aspects. Rev Infect Dis 3:254

23. Weibel RE, Vella PP, McLean AA, et al 1977 Studies in human subjects of polyvalent pneumococcal vaccines. Proc Soc Exp Biol Med 156:144

24. Zar JH 1974 Biostatistical Analysis. Prentice-Hall, Inc, Englewood Cliffs, NJ

25. Ziehelboin S, Somasy A 1981 Multiple antibiotic resistance in South African strains of Streptococcus pneumoniae: mechanism of resistance to $\beta$-lactam antibiotics. Rev Infect Dis 3:267

\title{
Maternal Smoking Increases Xenobiotic Metabolism in Placenta but Not Umbilical Vein Endothelium
}

\author{
DAVID K. MANCHESTER, NATALIE B. PARKER, AND C. MICHAEL BOWMAN \\ Departments of Pediatrics and Pharmacology, University of Colorado School of Medicine, \\ Denver, Colorado 80262
}

\begin{abstract}
It is unclear whether placental xenobiotic metabolism can protect the human conceptus. In particular, the role of placental metabolism of toxic components of cigarette smoke such as polycyclic aromatic hydrocarbons (PAHs) is poorly understood. We hypothesized that increased aryl hydrocarbon hydroxylase (AHH) activity observed in placentas from smokers might help clear PAHs from maternal circulation and thereby prevent transplacental induction of AHH by PAHs. Our studies of AHH activity in human placentas and umbilical vein endothelium support this premise. While AHH activity was significantly increased in placentas from smokers compared with activity in placentas from nonsmokers, AHH activity in
\end{abstract}

Received August 10, 1983; accepted March 13, 1984.

Address reprint requests to David Manchester, Department of Pediatrics, B-160, University of Colorado Health Sciences Center, 4200 E. Ninth Avenue, Denver, CO 80262 .

C. M. B. is a Clinician Scientist Awardee of the American Heart Association and recipient of a Faculty Development Award from the University of Colorado. This work was supported by grants from the American and Colorado Heart Associations, the University of Colorado, and National Institutes of Health Grant HD 12936. The protocol for this study was reviewed and approved by the Human Subjects Committees at University Hospital and Rose Medical Center, Denver, $\mathrm{CO}$.

\begin{abstract}
umbilical vein endothelium from these same pregnancies was unaffected by maternal smoking and remained low. In order to confirm that $\mathbf{A H H}$ present in endothelium was inducible, we also demonstrated dose-dependent increases in $\mathrm{AHH}$ activity in primary cultures of human umbilical vein endothelial cells exposed to PAHs. These findings may indicate first pass protection of the fetus by placental xenobiotic metabolism, or that endogenous factors suppress AHH induction in the fetus but not placenta. (Pediatr Res 18:1071-1075, 1984)
\end{abstract}

\section{Abbreviations}

AHH, aryl hydrocarbon hydroxylase PAH, polycyclic aromatic hydrocarbon

HEPES, 4-(2-hydroxyethyl)-1-piperazineethanesulfonic acid

Maternal cigarette smoking increases risks for spontaneous abortion, premature delivery, and fetal growth retardation and 